\title{
Über die durch Nekrosebazillen verursachten multiplen Leberabszesse der Rinder.*
}

\author{
Von \\ S. Yamamoto. \\ (Aus dem Veterinür-Puthologisshen Institut, Landuir'schaftliche Falıultüt, \\ Tokio Kaiserliche Lnitersität. Prof. Emoto. Direktor)
}

(Received for publication August 15, 1938)

Die Ätiologie der Abszesse in der Bauchhöhle der Rinder ist nicht einheitlich.

Primäre Abszesse können bei direkter Infektion der Bauchorgane durch offene penetrierende Verletzungen durch vom Pansen verdringende Fremdkörper entstehen. Und als die mit dem Fremdkörper verdringenden Eitererreger ist das Bacterium pyogenes am häufigsten bei erwachsenen Rindern. Diese Tatsache wurde erklärt auch in Japan bei Rindern.

Die Leber sitzt in Bauchhöhle nahe dem Pansen also natürlich auch in der Leber die Fremdkörperabszesse treten häufig auf. Aber solche Fremdkörperabszesse treten in der Regel einzeln auf.

Die multiplen Leberabszesse sind meisten sekundäre Abszesse, die hamatogen, cholangiogen, oder lymphogen entstehen können.

Hier ist eine Gruppe der multiplen Leberabszesse, die in der Anzahl der Präparate, die zu unserem Institut von Schibaura Schlachthof (Tokio) erhalten werden, häufig vorkommt, ohne Gram positive Corynebacterium pyogenes sondern mit Gram negativen schmalen Bazillen.

\section{Bakteriologischer Befund}

Etwa 2 Jahre zurück kultivierte ich diese Gram negative schmale Bazillen durch anaerobische Methode. Aber in jener Zeit es wurde geglaubt, dass die Nekrosebazillen seien etwas selten in Tierkrankheiten in Japan. Also dachte ich nicht diese Gram-

* Japanese abstract, pp. 212-213. 
negative anaerobe Bazillen seien die Nekrosebazillen. Und nur züchtete ich diese Organismen auf Leber-Leber-Bouillon weiter. Da am 10. Nov. 1937 beobachtete ich eine Nekrosebazillose des Hirsches von Ueno-zoologischem Garten und entdeckte, dass die früher vom Rinderleber-abszesse isolierte Gram negative anaerobe Bazillen zu den von diesem Hirsche gezüchteten Nekrosebazillen sehr ähnlich sind. Und da sammelte ich solche multiple Leber abszesse der Rinder und isolierte durch anaerobische Methode die Gram negativen Bazillen und während 2 Monaten bekam ich 17 Stämme von diesen Bazillen.

Hier schreibe ich kurz über die Eigenschaften dieser Bazillen. Morphologie: Dieșe kultivierten Bazillen sind fadenförmig etwa $1 \mu$ breit und längere $150 \mu$ lang, und allgemein etwas breiter und kurzer als der Stamm vom Hirsch. Die im Eiter liegenden Bazillen sind kürzer und schmaler als die neu kultivierten.

Ich finde keine Eigenbewegung und Sporenbildung. Die Bazillen farben sich mit Karbolfuchsin, Löflers Methylenblau oder mit Karbolthionin, jedoch nicht nach Gram. Mitunter zeigen die längeren Stäbchen und Fäden ungefärbte Lücken, die mit kurzen, zylindrischen, intensiv gefärbten stäbchenförmigen Abschnitten abwechseln, und schauen aus wie die Japanische Fahnenstange. In der Beobachtung mit Dunkelfeld zeigen diese Bazillen eine Form der Fasiformenbazillen, und jedes Ende ist schmaler als die ubrigen Teile des Stäbchens.

Kultur: Dieser Bazillus ist obligat anaerob. Er wächst bei Körpertemperatur in hochgeschichteten Leberagar mit Zusatz von 2 $\%$ igem Traubenzucker, 2\% Traubenzuckeragar, Leber-LeberBouillon, Leber-Bouillon mit Zusatz von Blutserum, Tarozzi-Bouillon mit Waselin (Chesebrough) aufgeschichtet gut.

In Leber-Leber-Bouillon wächst dieser Bazillus gut mit Gas. und Indolbildung, aber ohne Schwefelwasserstoffproduktion. Hirnbrei wird unter lebhafter Gasbildung rosarot verfärbt. Pathogenität: Kaninchen und Mäuse werden durch subkutane, intramuskuläre, und intraperitoneale Impfung mit diesen Bazillen leicht infiziert. Beim Kaninchen bei Infektion am Ohr erstreckt sich die trockene, käsige Nekrose des Gewebes auf den Kopf und 
den Hals hinab und in 20-30 Tagen führt den 'Tod herbei. Bei Infektion am Rückenunterhautgewebe senkt die trokene, käsige Nekrose des Unterhautgewebes mit vorangehendem Ödem fächerförmig unaufhörlich und endlich wird auf der Bauchseite grosse Masse der Nekrose gebildet und das Tier niederkauert sich und die Körpertemperature ist niederer als normal, und in etwa 1520 Tagen stirbt.

Bei weissen Mäusen bei Infektion an dem Schwanzwürzel entsteht die Nekrose des Unterhautgewebes und Muskeln, und der Tod folgt etwa 14 Tage nach der Impfung. Bei Infektion am. Schwanz, das Ende des Schwanzes verändert sich in trockene Gangrän und man kann ihn brechen wie ein Holzabfall.

Aber diese Bazillen von Rinderleberabszesse sind allgemein weniger virulent als der Stamm von Hirsch.

Dieses künstlich erzeugte Nekrosegewebe wird in Müllerscher Lösung gehärtet und durch die Schnittfarbung nach Jensen werden diese Bazillen schönrot gefarbt, und an der Grenze zwischen dem Ödem und dem abgestorbenen Gewebe finde ich diese Bazillen in enormen Mengen, in dicken Buscheln radiär angeordnet, die mit ihren Fäden senkrecht in das ödematöse Gewebe sich hinein erstrecken.

Mit obenerwähnten Fundamenten urteile ich diese Bazillen zu früher beschriebenen Nekrosebazillen zu entsprechen.

\section{Pathologischer Befund}

Nun schreibe ich über die Pathologie der multiplen Leberabszesse der Rinder von jenem Inhalt von dem ich obenbeschriebene Nekrosebazillenstämme bekommen konnte.

Makroskopischer Befund :

Diese Abszesse sind ziemlich haselnuss- bis walnussgross, in selteneren Fällen erreichen sie Taubenei- bis Hühnereigrösse, und treten in der Regel multipel, am zahlreichsten 72 haselnussgrosse Abszesse, die ich nur von der Oberfläche zahlen konnte. Wenn die Herde sitzen gerade unter der Serosa, so verdickt sich die sie bedeckende Serosa infolge der fibrinösen und fibrösen Peritonitis, und verklebt sich mit benachbarten Organen, meistens mit 


\section{dem Zwerchfell.}

Auf Durchschnitten durch diese erkrankte Leber beobachtete ich, dass die obenerwähnte Abszesse auch in der Tiefe des Organs auftreten, und ihr Sitz ist regellos, unabhängig vom Aufbau des Organs.

Hier makroskopisch unterscheide ich diese Abszesse in zwei grosse Gruppen, bezw. erstens in dem Eiter eine gelb-braune leidlich feste Masse haltende Form, ich nenne sie sequestrierte Form, zweitens in dem Eiter keine feste Masse nachweisbare Form, ich nenne sie erweichte Form.

Sequestrierte Form: Bei dieser Form, 5 Falle in meinen 17 Fallen, mit äusserer fester, derber, grauweisslicher bindegewebiger Kapsel sind nicht dick wie die erweichte Form, und von diesem umgegebenen Eiter sind grüngelb zäh und mit etwas süssem Geruche. Im Zentrum solcher Herde sitzt eine gelbbraune, etwas feste Masse, welche durch die histologische Untersuchung als Sequester erklärt wird.

Erweichte Form: Bei dieser Form, 12 Fälle in meinen 17 Fallen, äussere bindegewebige Kapsel entwickelt sich sehr gut und bisweilen dringt in dem Eiter Granulationsgewebe und scheint wie eine Actinomykose, und in dern Eiter finde ich makroskopisch Sequester nicht mehr.

Ausser diesen 2 Formen beobachtete ich einen Fall (Nr. 24) bei welchem in der Leber haselnuss- bis walnussgrosse Herde etwa gleichmässig durchsetzt wie bei den anderen 2 Formen und als multiple Leberabszesse ausschauen aber auf den Schnittflächen sind die Herde verändert zum Narbengewebe und von diesem Herde konnte ich nicht die Nekrosebazillen züchten. Solcher Fall muss im Schlachthof als eine Leberzirrhose gehalten werden.

Histopathologischer Befund:

Sequestrierte Forn: An im Zentrum der Herde liegender makroskopisch etwas fester gelbbrauner Masse fand ich durch Azanfarbung oder Weigertsche Elastikafärbung altes Lebergewebe besonders Blutgefasse, Glissonsche Scheide und Leberazini und Balken, aber mit Haematoxylin- Eosinfarbung gibt es ungefahr kein gesunder Zellkern, also erklärt es, dass diese Masse koagulations 
Nekrosegewebe its.

Der um diese Nekrosemasse liegende Eiter besteht aus veränderten polymorphkernigen Leukozyten und mononukleären Rundzellen. Und in diesem ziemlich durch Haematoxylin gefärbtem Eiter schwimmt hier oder dort mit Eosin intensiv gefärbte rote Masse, welche zu Actinomyces Druse sehr ählich ist. Ich zweifelte die Actinomycesmischinfektion und farbte die Schnitte durch Gram Weigert Methode. Aber in dieser Masse wurden keine Grampositiven Organismen gefunden, also diese Masse sind nicht die Drusen von Actinomyces bovis.

Durch Levaditi Imprägnation, mit welcher eben die etwas degenerierten Bazillen im Gewebe gut dargestellt werden können, eine buschige Masse der fadenfürmigen Bazillen, welche nach dem Vorschein den Nekrosebazillen sehr ähnlich sind, im Zentrum der Actinomyces Druse ähnliche gesammelte Zellenmasse beweist wird.

Und noch dazu diese Eosinophilemasse ist auch in den Herden, in welchen die Nekrosebazillen ganz rein wohnen, nachweisbar also denke ich diese Masse steht zu Nekrosebazillen in Beziehung, besonders in etwas älteren durch diese Bazillen verursachten Lebererkrankungen vorkommen.

Und in etwas frischen Herden, wie erster Fall, finde ich nicht diese Eosinophilemasse und durch Levaditi Imprägnation die Bazillen liegen gleichmässig in dem Eiter, und bilden nicht das buschige Bündel.

Dann denke ich, dass diese Eosinophilemasse aus den Bündeln der Nekrosebazillen und diese umgebenen veränderten Leukozyten und anderen bestehen, und sind der Stützpunkt der Bazillen gegen alle Schutzwirkuug der Gewebe.

Um diese Eiterzone herum sitzt die sogennante Pyogenemembran, welche an Eiter anstossende Zone aus mit gelapptkernigen Leukozyten (Oxydasereaktion positiv) und durch Unna-PappenheimFärbung positiv dargestelte Plasmazellen infiltriertem Granulationsgewebe besteht.

Und hier betone ich, dass an die Grenzshicht der Granulationsgewebe gegen den Eiter viele schrecklich grosse fetthaltige Makrophagen eine Züge bilden. Und auf Haematoxylin-Eosin Prä- 
parat scheint diese Züge hell.

Die äusseren Teile der Pyogenemembran, nach dem gesunden Gewebe, besteht dagegen aus kernarmen Fibrillen.

Wegen dieser fetthaltigen Makrophagenschicht scheint makroskopisch die innere Fläche der Granulationsgewebe gelblich, aber bei der Mischinfektion der $\mathrm{H}_{2} \mathrm{~S}$ bildende Bazillen, sie scheint leicht graugelb wegen der dort entstandenen winzigen Pseudomelanose. Also solches Material ist ungüstig als Material von welchem die Nekrosebazillen żu isolieren.

Übersichtlich sind diese Befunde die Erweichung der an Zentrum liegenden Nekrosemasse welche als Sequester von umgebenem Gewebe isoliert, die Sequestration, und die Organisation; und die Abkapselung.

Erweichte Form: Bei dieser Form gibt es keine Sequester im Eiter. Aber die Natur des Eiters nnd der Granulationsgewebe ist ganz ähnlich zu der sequestrierten Form. Nur die Entwicklung der Granulationsgewebe fortschreitet und die Grenzschicht derselben gegen dem Eiter ist sehr ungleich, besonders bei einigen Fällen, die Erwachsung der Granulationsgewebe sehr gut und die Eitermasse bleibt inselförmig hier oder dort im Granulationsgewebe, solche Herde scheinen makroskopisch als eine Actinomykose.

Nun denke ich auf folgenden Gründen, dass die obenerwähnten 2 Formen der multiplen Leberabszesse der Rinder, die auf den 2 verschiedenen Stufen der Krankheit liegende dieselbe Lebererkrankung zu sein.

1) Von jeden Formen konnte ich die Nekrosebazillen züchten, also diese Krankheiten sind ätiologisch identisch.

2) Dis Grösse der Herde und der auftretende Modus sind sehr ähnlich jeden Formen.

3) Die Natur der Granulationsgewebe und des Eiters ist makroskopisch und histologisch ganz ähnlich.

4) In einigen erkrankten Lebern sind diese 2 Formen der Herde gemischt, die grösseren Herne zeigen sequestrierte Formen und die kleineren Herde zeigen erweichte Formen.

Dann bei erweichten Formen sind die Gewebsreaktionen, die Erweichung der Nekroseherde, die Sequestration, und die Organi- 
sation, ziemlich fortgeschritten als bei sequestrierter Form.

Also bei gleicher Grösse der Herde die erweichte Formen sind auf dem vorgetretenen Stufen der Krankheitsdauer als die sequestrierten Formen. Aber natürlich bei kleineren Herden die obenerwähnte Gewebsreaktionen können schneller als bei grösseren Herden vollenden.

Hier vergleiche ich diese Lebererkrankungen, besonders die sequestrierte Form mit der sogenannten Nekrobazillose der Rinderleber, die durch die Nekrosebazillen verursacht in der Mehrzahl der Fälle haselnuss- bis walnussgrosse multiplen Nekroséherde auftretenden Lebererkrankung, welche ich nur einmal in 5 Jahren in vom Schlachthof zu unserem Institut gebrachten pathologischen Organen beobachtet habe.

Und auch hier beurteile ich aus folgenden Gründen, dass diese 2 Krankheiten identisch sind.

1) Diese 2 Krankheiten sind ätiologisch identisch.

2) Die Grösse der Herde und der auftretende Modus sind sehr ähnlich.

3) Bei beiden Krandkheitsherden sitzen im Zentrum der Herde das typische Nekrosegewebe. Die Demarkation, die Gewebsreaktion um den frischen Lebernekroseherd muss eine junge Form der Sequestration sein. Also gibt es histologisch verbundene Übergänge $z$ wischen diesen 2 Krankheitserscheinungen.

Nun es wird erklärt,dass diese 3 Formen der Lebererkrankungen, sogenannte Nekrosebazillose der Rinderleber,die 2 Formen der. multiplen Leberabszesse der Rinder, identisch sind und stehen auf den 3 verschiedenen Stufen derselben Krankheit. Die sogenannte Nekrosebazillose der Rinderleber ist jüngst, die sequestrierte Form der multiplen Leberabszesse ist mittler, die erweichte Form derselbe ist älter, und dazu der zu Narbe verheilte Fall (Nr. 24, welcher vielleicht im schlachthof als die Leberzirrhose gehalten wird, kommt als die älteste.

Die Nekrosebazillen dürften in der Regel auf dem Wege der Pfortader vom Darm oder auf anderem Wege der Leber zugeführt werden.

Und am Ort ihrer Ansiedelung bewirken sie infolge ihrer 
Vermehrung und Absiedelung durch toxische Produkte eine umschriebene, fortschreitende Koagulationsnekrose des Lebergewebes. Das Auftreten sehr zahlreicher Nekroseherde in der Leber füht meist den Tod herbei oder verursacht schwere Erkrankung.

Bei günstigem Verlaufe erleiden die nekrotischen Leberherde sekundäre Veränderungen, die Gewebsreaktionen, demarkierende Entzündung in der Peripherie der Herde. Dann begann die Demarkation und Verflüssigung der Nekroseherde von Peripherie derselben.

Der Nekroseherd isoliert sich von Peripherengewebe und wird zu Sequester. Und andererseits die démarkierende Entzündung fortschreitet und da gebildetes Granulationsgewebe macht gegen die innere Seite mit zahlreichen Makrophagen und Mikrophagen die Verflüssigung und die Resorption der Nekrosegewebe und an äuserer Seite verändert sich zum Bindegewebe und diese Herde kapseln ab.

Bei dem noch günstigeren Fall schreitet die Resorption, und Organisation sehr gut fort und die Herde veränderen sich zu Narbe und können heilen.

Hier denke ich an die Verhältnisse zwischen der Häufigkeit dieser verschiedenen Formen der Nekrobazillose der Rinderleber und der Verlaufsdauer derselben. Der Verlauf der seltenen Koagulationsnekrose ist der kürzeste, und der Verlauf der sequestrierten Form ist nächst kurz und der Verlauf der erweichten Form ist länger, und die zur Narbe verheilte Form dauert zum Tode des Tieres.

Bis Heutzutage wurde in Japan die Nekrobazillose der Rinderleber besonders mit typischen Koagulationsnekrose etwas selten beobachtet, aber nach den obenerwähnten Ergebnisen enthält diese Krankheit diese verschiedene Stadia der Krankheit sind nicht selten vielmehr verhältnismässig häufig auch in unserem Vaterland.

\begin{tabular}{|c|c|c|c|c|c|}
\hline $\begin{array}{l}\text { Nummer d. } \\
\text { Fälle }\end{array}$ & $\begin{array}{l}\text { Anzahl d, aussen- } \\
\text { befindlichen Herde }\end{array}$ & $\begin{array}{l}\text { Grösse d. } \\
\text { Ferde }\end{array}$ & $\begin{array}{l}\text { Form d. } \\
\text { Herde }\end{array}$ & $\begin{array}{l}\text { Eosinophile } \\
\text { Masse }\end{array}$ & Bakterien \\
\hline 1 & 26 & hn & sequ. & - & Gram - B. \\
\hline 2 & 6 & hn & erw. & + & Gram - B. \\
\hline
\end{tabular}




\begin{tabular}{|c|c|c|c|c|c|}
\hline 3 & 4 & hn-wn & erw. & + & Gram - B. \\
\hline 4 & 72 & hn-wn & sequ. & + & Gram - B. \\
\hline 5 & 52 & hn & erw. & + & $\begin{array}{c}\text { Gram - B. } \\
\text { Gram + B. }\end{array}$ \\
\hline 16 & 6 & hn & sequ. & + & Gram - B. \\
\hline 17 & 1 & he & erw. & - & Gram - B. \\
\hline 18 & 1 & he & sequ. & + & Gram - B. \\
\hline 21 & 2 & wn & erw. & + & Gram - B. \\
\hline 22 & $\mathbf{1}$ & he & erw. & - & Gram - B. \\
\hline 23 & 3 & wn & erw. & - & Gram - B. \\
\hline 24 & 8 & hn & Narbe & - & - \\
\hline 29 & $\mathbf{1}$ & hn & erw. & + & Gram - B. \\
\hline 32 & $\mathbf{1}$ & wn & erw. & - & Gram - B. \\
\hline 31 & 2 & wn & erw. & + & Gram - B. \\
\hline 35 & Stück & wn & erw. & - & Gram - B. \\
\hline 32 & wn & sequ. & + & Gram - B. \\
\hline
\end{tabular}

Anm. hn: Haselnussgross wn: Walnussgross he : Hühnereigross sequ : sequestrierte Form erw : erweichte Form

\section{Zusammenfassung}

1) Auch in Japan gibt es verhältnismässig viele durch Nekrosebazillen verursachte multiple Leberabszesse der Rinder.

2) Verfasser beobachtete 2 Formen dieser Abszesse, die sequestrierte Form und die erweichte Form.

3) Und erklärt, dass diese 2 Formen der multiplen Leberabszesse und die sogenannte Nekrobazillose der Rinderleber aus mehreren Gründen identisch sind, und die letztere dem jüngsten, sequestrierte Form der Abszesse dem mitten und die erweichte Form dem älteren Stadium derselben Krankheiten entsprechen. Bei günstigstem Fall die Herde verändern sich zu Narbe und können heilen. 


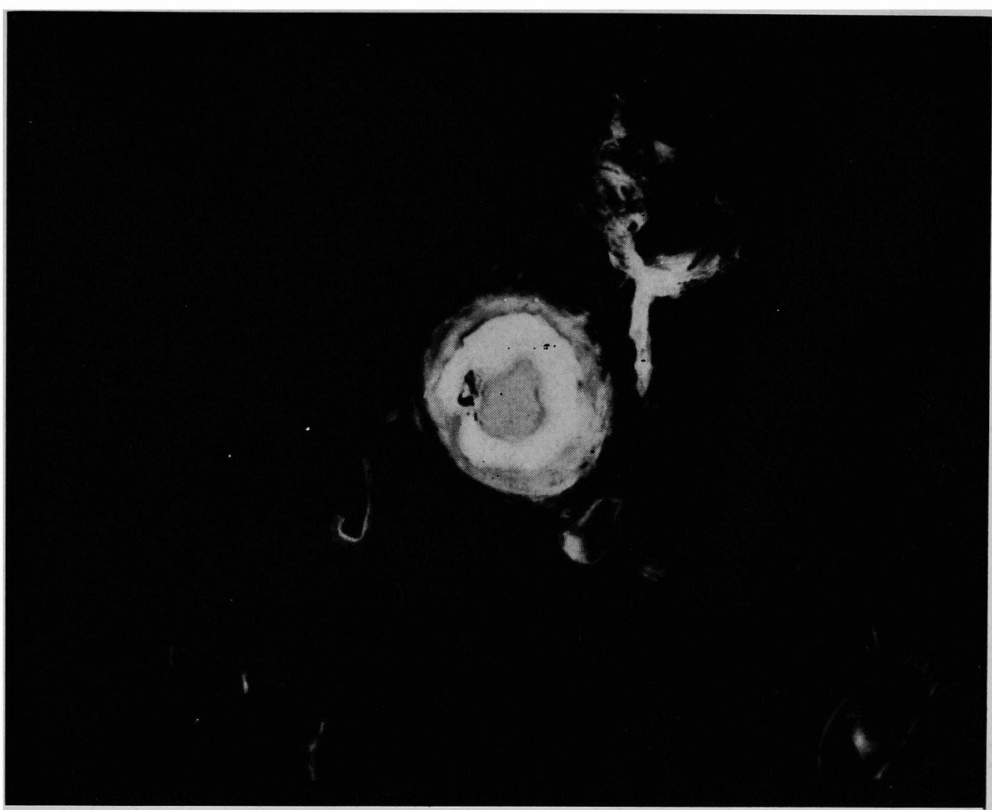

Fig. 1

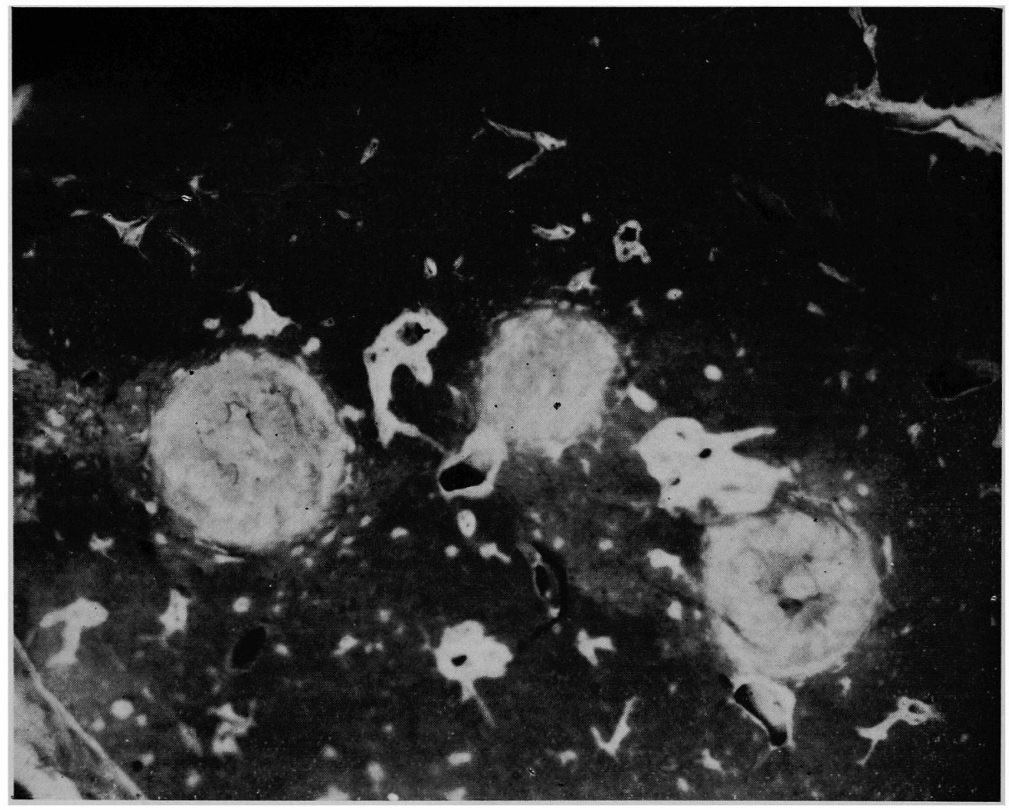

Fig. 2 


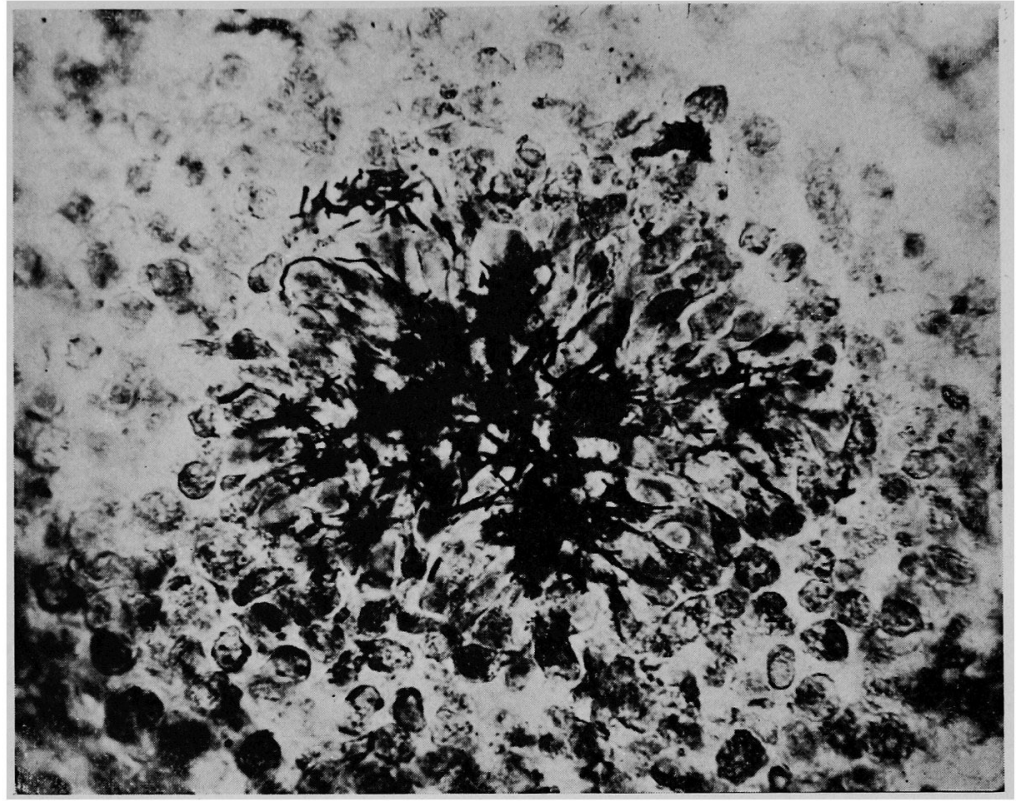

Fig. 5

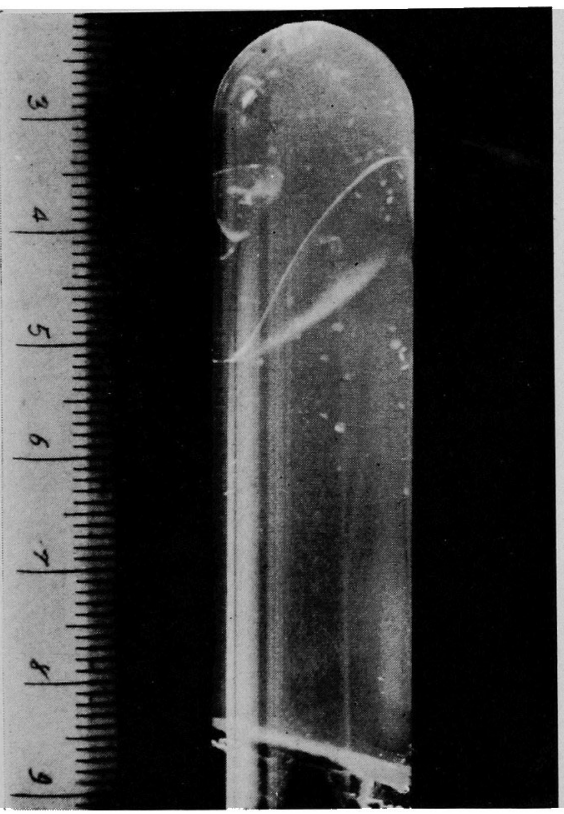

Fig. 6

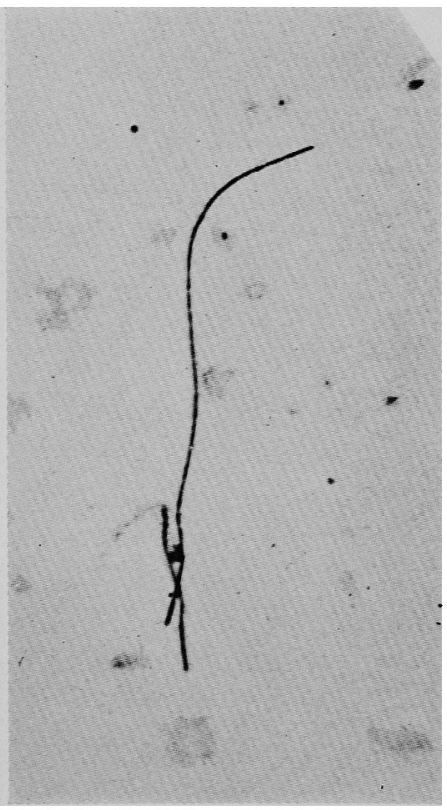

Fig. 7 


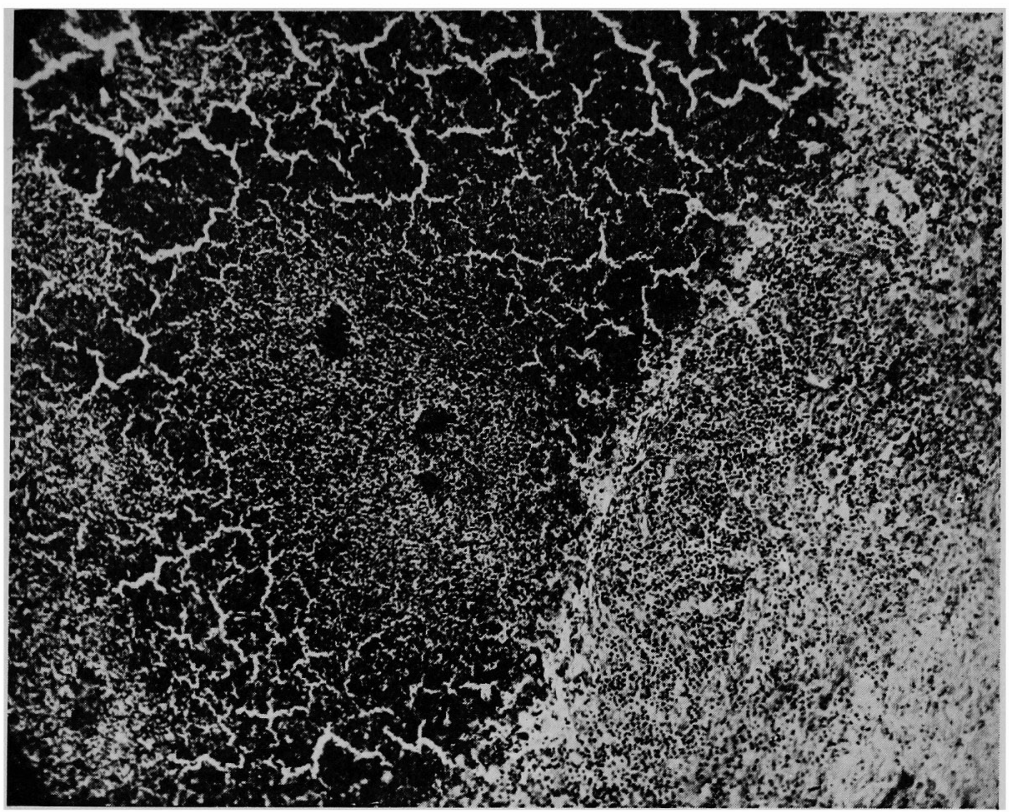

Fig. 3

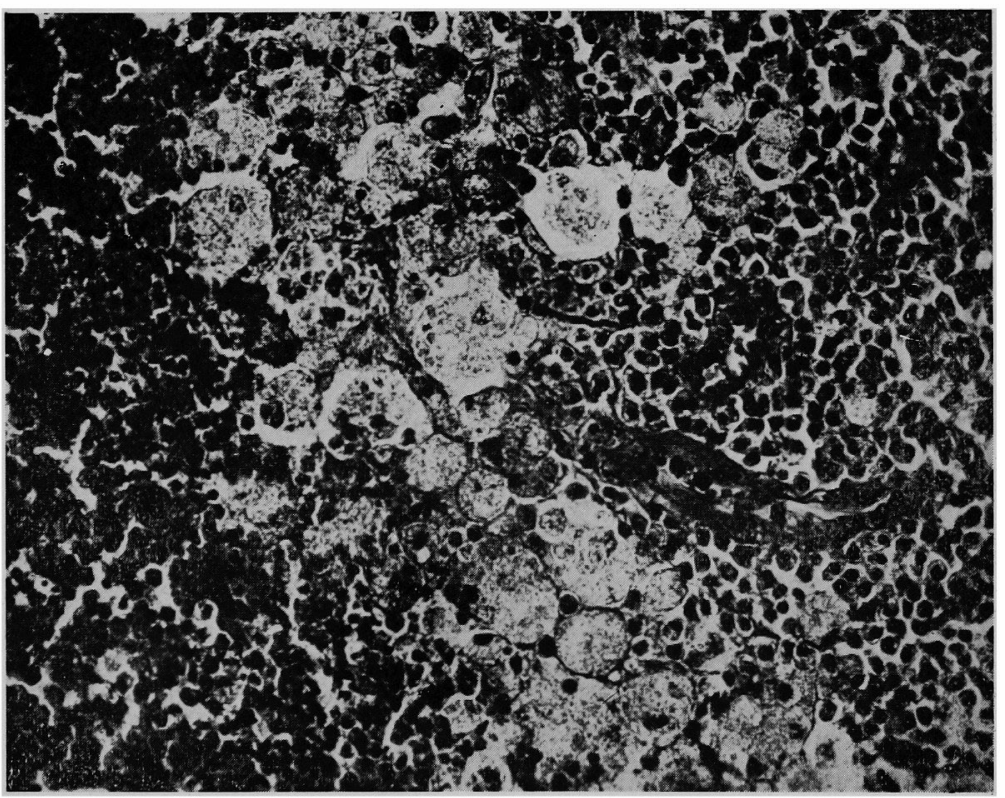

Fig. 4 
Über die durch Nekrosebazillen verursachten multiplen Leberabszesse der Rinder. 49

\section{Literatur}

(1) Albrecht B. Infektionen durch Nekrosebacillen. In kolle Kraus Uhlenhuth Handbuch der Pathogenen Mikroorganismen 3. Aufl. Gustav Fischer Jena 1928 Bd. 5 S. 673.

(2) Bang B. Über die Ursache der Lokalen Nekrose. Bernhard Bang selected works. Humphrey Milford. Oxford University Press London 1936.

(3) Bongert J. Bakteriologische Diagnostik. 7 Aufl. R. Schoetz Berlin 1927.

(4) Carpano M. Die nekrotisch-gangränösen Affektionen in der Veterinärpathologie. Zhl, f. Bakt, I. Orig., 1914 Bd. 74 S. 225.

( 5) Ellermann. Einige Fälle von bakterieller Nekrose beim Menschen. Zbi. f. Bakt. I. Orig., 1905 Bd 38, S. 383.

(6) Ellinger. Zur Kasuistik der übertragłbaren bösartigen Scheidenentzïndungen des Rindes mit besonderer Berücksichtigung der Wirkungen des Nekrosebacillus zugleich ein Beitrag zur Lehre von der puerperalen Infektion. Berl. T. W. 1903 S. 25.

(7) Jensen C. O. Die vom Nekrosebacillus (Bac, necroseos) hervorgerufenen Krankheiten. In Kolle Wassermann. I Landbuch der Pathogenen Mikroorganismen, 2 Aufl. Gustav Fischer. Jena 1913 Bd. 6 S. 234.

(8) Juest E. Handbuch der speziellen pathologischen Anatomie der Haustiere. 2 Auflage R. Schoetz. Berlin 1936.

(9) Kaspar F. u. Kern. Weitere Beiträge zur Atiologie der pyämischen Prozesse. ZbI. f. Bakt., I. Orig., 1910 Bd. 55 S. 97.

(10) Lund L. Pathologische Histologie der Haustiere. Schaper. Hannover 1931.

(11) Schmidt F. Nekrobacillose bei Saugferkeln. Berl. T. W. 1923 S. 94.

(12) Seifried $O$. Die wichtigsten Krankheiten des Kaninchens. J. F. Bergmann, Munchen 1927.

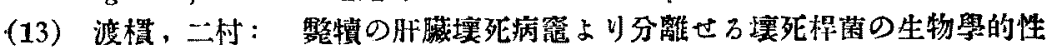

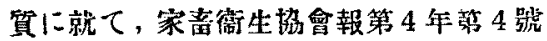

\section{TAFELERKL ÄRUNG}

Fig. 1. Seque itrierte Form der multiplen Leberabszesse. Durchschnitt durch den Herd. Natïrliche Grösse.

Fig. 2. Erweichte Form der multiplen Leberabszesse. Durchschnitt durch den Herd. Natürlic he Grösse.

Fig. 3. Mikroskopisches Bild der inneren Seite der Abszesswand.

links: Eiter mit 3 Eosinophilemasse.

rechts: Granulationsgewebe. $(\times 70)$

Fig. 4. Mikroskopisches Bild der Abszesswand und Eiter, an der Grenzschicht viele Makrophagen sind deutlich. $(\times 283)$

Fig. 5. Levaditi Präparat der Fosinophilemasse im Eiter. $(\times 900)$

Fig. 6. Leberagar Schüttelkultur 4 Tage alt. (Infra-rot-photographie)

Fig. 7. Neu kultivierte Bazillen. $(\times 900)$ 


\title{
牛ノ肝臟ノ壞死桿菌二起因スル多發性膿瘍二就广*
}

\author{
山本 俏 太 郎 \\ （東京帝國大學農學部獸醫學科病理學数室）
}

(昭 和 13 年 8 月 15 日受附)

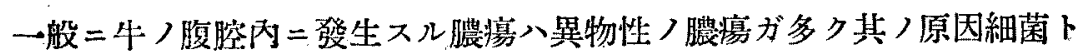
シテ八種々ナル化膿菌中特=化膿楻菌ガ目立ツテ居ルト云フ事ニナツテ居

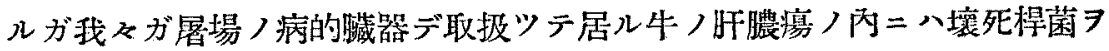
原因トスルモノガ相虽二多イ私八最近瓜生學士ノ御盡力ニヨツテ斯樣ナモ

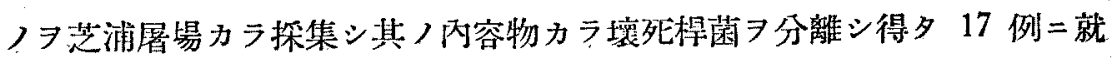
キ病理學的考察 行ツタ

肉腿的二此ノ種ノ膿瘍八多發性ノモノガ多ク大キサ八溙惯大カラ胡桃大

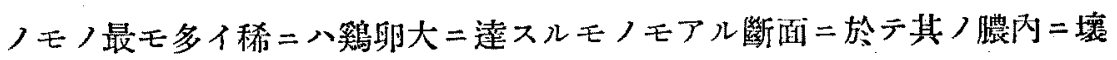
死片シ含有シテ居ルモノト然ラザルモノガ區別サレル

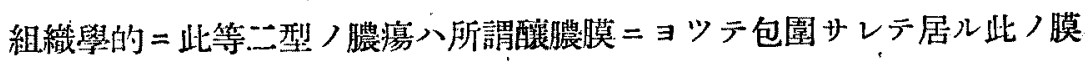
八內二近ヅタ程幼弱ナ肉芽組織カラナツテ居り多形核白血球，ぶらずま細 胞等ガ多數浸潤シテ居り特二膿二橓接シタ所二八脂肪 喰細胞ガ列ヨナシテ配列シテ居ル人まときしりん，えまじん染色デハ此， 細胞體入非掌 $=$ 朋カルク見エルノデ弱撗大デ八此ノ大喰細胞ノ配列線入明 カルイ帶トナツテ見ェル此ノ膜二包園サレル膿八主トシテ變性シタ白血球 及單核圓形細胞等カラナツテ居リ或ル例デハ其ノ內ノ所々二えおじん=漫 染スル丁度放線狀菌ノ菌塊ノ樣ナモノガ見エル之ハぐらむ染色 队 $=$ Actinomyces Bovis 認メナイ其ノ代り Levaditi ノ鍍銀法=ヨリ 形ノ上デ八壞死桿菌卜區别出來ナイ長絲状菌ガ束ニナツテ居ルノガ認メラ レル郎チ此レ八壞死柏菌ノ束

* 原䔔歐文 40-49 頁堅炤 
等カラナツテ居ルモノデアル

膿內二壞死片ヨ認メルモノデハ此ノ膿ノ中心部二組織學的二碓カ二離方 ヨ認メル事ガ出來ル

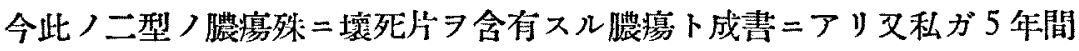

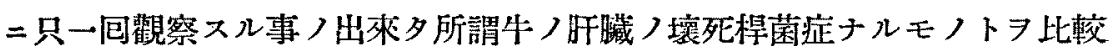

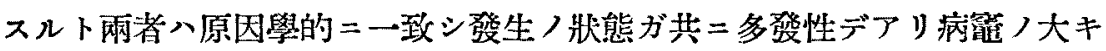

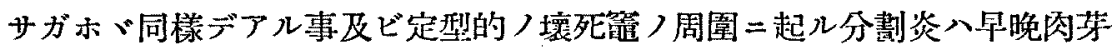
組織ノ發達ニョツテ壤死籠ノ分離 一ノ病變ノ時期ノ差ニヨル形態ノ差異ト認ムベキモノト考へラレル此ノ他

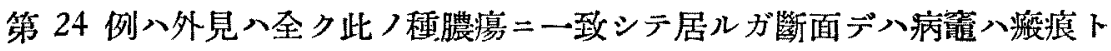
化シ最早其ノ內カラ壞死桿菌ヨ分離シ得ナカツタモノデアル

今私ガ採集シ得夕各病型ノ例數カラ其ノ各飞ノ經過期間 7 推定スル事 許サル、ナラバ極稀レナ定形的ノ壞死藍形ノモノ八經過期間最モ短カク速

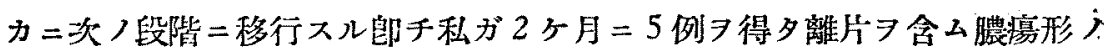
モノトナル此レ八前者ヨリ八經過期間八堅イガ次ノ 12 例习得夕軟化つ進

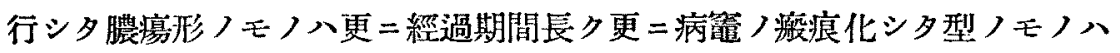
動物ノ生命卜共=繼續スルモノデアロウ斯樣二以上ノ各型ヨ總べデ裳死秙 菌症トシテ總括シテ考へルト本邦二於テモ本病ハ決シテ少イモノデハナイ ト云フ事ニナル 